\title{
Chemical Effectiveness of Salvadora persica and Commercially Available Whitening Toothpaste on Preventing Tea and Chlorhexidine Stain (in vitro study)
}

\author{
Erlina Sih Mahanani ${ }^{1}$ \\ Erry Mochamad Arief ${ }^{2}$ \\ Puteri Ezdiani Binti Mohamed Ismail ${ }^{2}$ \\ ${ }^{1}$ School of Dentistry, Faculty of Medical and Health Science \\ Muhammadiyah University of Yogyakarta, Indonesia \\ ${ }^{2}$ School of Dental Sciences, Universiti Sains Malaysia \\ Kota Bharu, Kelantan, Malaysia \\ E-mail: erlinasihmahanani@yahoo.co.id \\ Received January 27, 2011; Accepted July 14, 2011
}

\begin{abstract}
Salvadora persica, a plant that contains a wide range of healthy components, has been used as chewing stick for ages to maintain good oral hygiene and currently has been approved to remove stains. However, its stain-preventing effect is still under investigation. This study aimed to investigate the effectiveness of Salvadora persica and commercially available whitening toothpastes on preventing tea and chlorhexidine stains. Sixty clear acrylic blocks were used and divided into 3 groups, 20 for each group. First group was treated with drinking water, second with commercially available whitening toothpaste and third with whitening toothpaste containing Salvadora persica extract. Baseline measurement by spectrophotometer was taken before starting the procedure. All specimens were immersed in artificial saliva for 2 minutes, rinsed in distilled water and exposed in $0.2 \%$ chlorhexidine and tea solution. These cycles were performed 8 times a day for 5 days. Intervention with whitening toothpaste was done for 2 minutes; twice a day. Eventually, all blocks were removed, washed and dried. Stain was assessed by spectrophotometer and visual assessment using Lobene stain index (1968). This study results showed significant differences among groups (Kruskal-Wallis test, $p<0.001$ ) and Salvadora persica extract was found to be more effective than commercially available whitening toothpaste on preventing stain formation.
\end{abstract}

Keywords: Salvadora persica, preventing stain, whitening

\section{Introduction}

Salvadora persica is a plant that has been being used to form miswak (a chewing stick), as a modal to maintain oral hygiene. The miswak is made from various parts of Salvadora persica. It has been known for centuries and used since pre-
Islamic custom especially by ancient Arabs in order to have white and shiny teeth. The benefits of miswak in maintaining good oral hygiene have also been mentioned in several hadiths (Islamic script). Nowadays, the miswak has been being used widely especially among Moslems ${ }^{1,2}$. The effectiveness of Salvadora persica in maintaining good oral hygiene 
and dental health has been proven in several studies. Its action includes cleaning oral cavity, whitening the tooth, promoting periodontal health as well as preventing calculus formation and bad breath either through mechanical or pharmacological action ${ }^{3}$. Furthermore, it is also known to have antibacterial, anti-caries, anti-periopathic and antifungal properties $^{4-7}$.

The natural color of permanent teeth is largely determined by dentine and modified by thickness and translucency of the overlying enamel. Discoloration of teeth may occur by deposition of various pigment into or onto the teeth. Causes of discoloration are usually classified as intrinsic and extrinsic stains ${ }^{8,9}$. Furthermore, the causes of extrinsic staining can be divided into 2 categories: those that are incorporated into the pellicle and produce stain as a result of their basic color, and those which lead to stains by chemical interaction at the tooth surface. The chromogens from dietary sources are taken up by the pellicle and the color imparted is determined by the natural color of the chromogen ${ }^{10}$.

Study by Moran ${ }^{9}$ and Addy ${ }^{10}$ clearly showed that extrinsic stains become internalized via multiple ways: through enamel defects or cracks, or due to dentine exposure. The most common deposited sites of extrinsic stains appear to be on or in the acquired pellicle. A study done by Vogel ${ }^{11}$ showed that the components within the food-beverages and tobacco are the most common chromogens in the mechanism. The Vogel's findings was also supported by Walsh et al., ${ }^{12}$ in which extrinsic stain may be due to superficial staining from dietary sources such as tea, coffee and red wine or chemical solutions such as chlorhexidine on mouth rinses. Walsh ${ }^{12}$ also mentioned that extrinsic stains can be removed either through physical or chemical means such as tooth brushing and chloride in toothpaste.

Nowadays dental aesthetics are highly regarded. Tooth whitening products demand from consumers or patients was increase. Various toothpaste products claiming to have potential to remove or prevent stain formation were already available on market though its effectiveness was unclear. The objective of this study was to investigate the effectiveness of Salvadora persica and commercially available whitening toothpastes on preventing tea and chlorhexidine stain.

\section{Materials and Methods}

This randomized in vitro study was carried out on Craniofacial Laboratory of The Universiti Sains Malaysia in Kubang Kerian, Malaysia. The applied methods on this study was approved by Research Ethics Committee of The Universiti Sains Malaysia number USMKK/PPP/JEPem.202.3(11). Sixty clear acrylic blocks in $1 \times 1 \times 3.5 \mathrm{~cm}^{3}$ dimension were prepared to fit the specimen chamber of a spectrophotometer. A baseline measurement was taken for each block before starting the procedure. The specimens were then divided into 3 groups with 20 clear acrylic blocks on each group. First group was treated with drinking water as a control, second with commercially available whitening toothpaste and third with whitening toothpaste containing Salvadora persica extract.

Staining procedure cycles of all specimens were done by immersion in artificial saliva for 2 minutes to stimulate acquired pellicle layer formation on acrylic surface. After 2 minutes, all blocks were rinsed in distilled water and exposed for 2 minutes with $0.2 \%$ chlorhexidine solution. Following this, blocks were carefully removed, washed and placed in standard solution (mix at $50^{\circ} \mathrm{C}$ ) for 2 minutes. The cycles were repeated 8 times a day ${ }^{13}$ for 5 days and the blocks were remained in artificial saliva between the cycles.

Intervention by the application of drinking water, Salvadora persica (Safi $^{\mathrm{TM}}$ Kayu Sugi, Winpro Unza, Malaysia) or commercially (Colgate Herbal, Colgate-Palmolive Company, USA) available whitening toothpaste was done twice a day at $09.00 \mathrm{am}$ and 04.00 pm for 2 minutes. After 5 days, all blocks were removed from the experimental cycles, washed in distilled water and dried. Staining intensity was assessed by visual assessment using Lobene stain index ${ }^{14}$. Kruskal-Wallis statistical analysis was employed to compare stain preventing effect on day 5 among all groups. 


\section{Results}

Median and IQR (spectrophotometer) value of baseline spectrophotometer evaluation on clear acrylic block were showed on Table 1. After undergoing several cycles for 5 days, stain was found on the acrylic block. Stain color intensity was significantly different among treatment groups $(p<0.001)$ as shown on Table 2 . Specimens on Salvadora persica whitening toothpaste treated group showed the lowest color intensity value or less staining formation than others. The following table is Lobene Stain Index reading on day 5 of staining (Table 3). The result shows that Group C was effective in preventing stain formation.
Figure 1 showed stain formation progress on each experimental group from day 1 to 5 . It was demonstrated that stain formation on Salvadora persica Whitening Toothpaste Group was the slowest and the fastest was that on Commercial Whitening Toothpaste Group. Table 3 was described visual observation on stain intensity according to Lobene Stain Index result after 5 days. On Drinking Water Group, all specimens showed heavy stain $(n=20)$ and most of specimens ( $n=19)$ on Commercial Whitening Toothpaste Group indicating similar intensity. Only 1 specimen on Commercial Whitening Toothpaste Group showed moderate stain formation. On Salvadora persica Whitening Toothpaste Group, 18 specimens showed moderate stain formation and the remaining 2 indicated heavy stain formation.

Table 1. Spectrophotometer reading result before staining cycles

\begin{tabular}{lcccc}
\hline & \multicolumn{4}{c}{ Comparing numerical variable between groups } \\
\hline Group/Variable & $\mathrm{n}$ & Median (IQR) & $\mathrm{X}^{2}$ statistic & $\mathrm{P}$ value \\
Drinking Water & 20 & $0.207(0.059)$ & 2.22 & \\
Commercial Whitening Toothpaste & 20 & $0.217(0.079)$ & $(2)$ & $<0.331$ \\
Salvadora persica Whitening Toothpaste & 20 & $0.223(0.077)$ & & \\
\hline
\end{tabular}

Table 2. Spectrophotometer reading on day 5

\begin{tabular}{lcccc}
\hline & \multicolumn{4}{c}{ Comparing numerical variable between groups } \\
\hline Group/Variable & $\mathrm{n}$ & Median (IQR) & $\mathrm{X}^{2}$ statistic & P value \\
Drinking Water & 20 & $0.894(0.313)$ & 41.58 & $<0.001$ \\
Commercial Whitening Toothpaste & 20 & $1.219(0.254)$ & $(2)$ & $<$ \\
Salvadora persica Whitening Toothpaste & 20 & $0.660(0.178)$ & & \\
\hline
\end{tabular}

Table 3. Lobene Stain Index on Day $5 f$

\begin{tabular}{|c|c|c|c|c|c|}
\hline \multirow{2}{*}{ Group } & \multicolumn{4}{|c|}{ Grade } & \multirow{2}{*}{ Total (\%) } \\
\hline & 3 & 2 & 1 & 0 & \\
\hline Drinking Water & 20 & 0 & 0 & 0 & 33.3 \\
\hline Commercial Whitening Toothpaste & 19 & 1 & 0 & 0 & 33.3 \\
\hline Salvadora persica Whitening Toothpaste & 2 & 18 & 0 & 0 & 33.3 \\
\hline Total (\%) & 68.3 & 31.7 & 0 & 0 & \\
\hline
\end{tabular}

Key: $0=$ No stain $1=$ Light stain $2=$ Moderate stain

3 = Heavy stain 


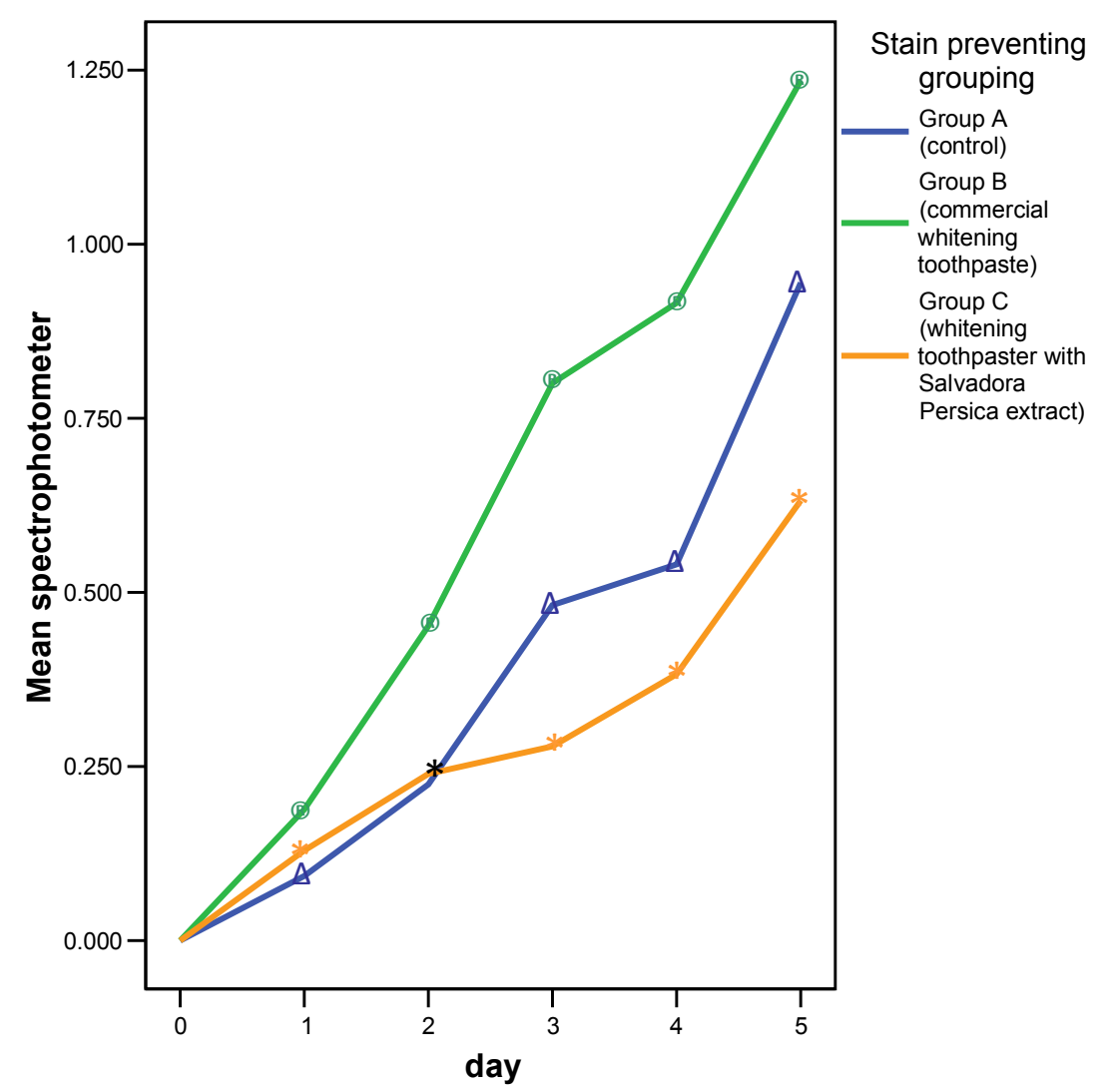

Figure 1. Progression of stain formation

\section{Discussion}

Stain formation is a continuous process that happens every day in human life. Several studies were shown tooth staining formation after chlorhexidine mouthwash use. Moreover, staining formation were more severe with consuming greater quantities of chromogens like of tea, coffee and chemical beverages. Previous laboratory and clinical study reported that chlorhexidine and tea were stronger than coffee in inducing staining formation ${ }^{15}$. Chlorhexidine precipitates anionic chromogens from dietary and produces stain complexes that we have seen clinically ${ }^{16,17}$. In this study, the specimens were stained with tea solution at $50^{\circ} \mathrm{C}$. Stain formation was significantly influenced by tea temperature and maximum staining effect of tea was at $50^{\circ} \mathrm{C}$. However, chlorhexidine temperature did not influence staining ${ }^{13}$. Artificial saliva was used as replacement for human saliva throughout this study to stimulate acquired pellicle layer formation on acrylic surface. Direct extrinsic staining occurs when chromogens on dietary source incorporates into acquired pellicle. On the other hand, metal salts and cationic antiseptics promote indirect stain formation on the tooth's surface via chemical reaction ${ }^{10}$. To demonstrate the staining effect, many dental researchers employed stain formation or stain removal models using clear acrylic block ${ }^{15,18}$. Clear acrylic block was used as specimen due to its similar manner to enamel on stain formation in or on the tooth 7 . Tea and chlorhexidine-induced stain formation on clear acrylic block model was used in this study to evaluate different whitening toothpaste potential on staining prevention.

In this study, we employed Salvadora persica whitening toothpaste contains of calcium carbonate, water, sorbitol, silica, sodium lauryl sulphate, cellulose gum, flavor, sodium bicarbonate, sodium saccharin, sodium monofluorophosphate and 
Salvadora persica extract. Meanwhile, commercial whitening toothpaste used in this study contains of calcium carbonate, water, sorbitol, hydrated silica, sodium lauryl sulphate, flavor, sodium monofluorophosphate, sodium carbonate, cellulose gum, sodium saccharin, carrageenan, xanthan gum, methylparaben, propylparaben, Melissa officinalis extract, Lonicera caprifolium extract, Citrus medica, limonum oil, pearl powder, $\mathrm{Cl} 77492$ and $\mathrm{Cl} 74260$.

It was found that Salvadora persica whitening toothpaste showed the most effective action on preventing stain formation, compared to commercial whitening toothpaste or drinking water. This was assumed to occurs by the action of Salvadora persica extract which contained high concentration of chloride, silica and sodium bicarbonate. This was supported by multiple studies performed since 1970 which shown that these chemical components were very effective to remove stains. A study done by Almas $^{2}$ proved that each chemical component in Salvadora persica has its own beneficial action in removing stains, preventing calculus formation, preventing plaque formation and other functions to maintain tooth shape and natural color.

Less stain prevention effects of commercial whitening toothpaste which was used in this study also explained Salvadora persica whitening toothpaste better stain prevention result. The commercial whitening toothpaste contained only general ingredient of whitening toothpaste (silica, calcium bicarbonate) and special blend of herbs (lemon extract, honeysuckle, pearl powder). The manufacturer stated that these components, especially herbs, acts only as unique flavorer and gives the sense offreshness in the mouth ${ }^{19}$. Its disadvantage of not having high concentration of chloride, one of the most important chemical components to prevent stains formation, was another reason for this lack of stain prevention effect.

There were multiple reason why drinking water showed better staining prevention potential than commercial whitening toothpaste in this study. First, it was probably due to drinking water composition which did not determined in this study. Source of water and type of filter system influence water composition and contents of the water itself may potential to prevent stain formation. Furthermore,
$\mathrm{pH}$ of water plays an important role on staining prevention. A study by Richard et al. ${ }^{20}$ proved acidcontaining paste potential to remove white, yellow and brown stain from enamel through microabrasion action. In this study, $\mathrm{pH}$ of the drinking water was 5.9, more acidic than the commercial and Salvadora persica whitening toothpaste which were 9.15 and 9.90 , respectively.

\section{Conclusion}

Whitening toothpaste containing Salvadora persica extract showed better staining prevention potential, compared to drinking water and commercial whitening toothpaste. Salvadora persica whitenting toothpaste ability to prevent stain formation was largely due to its chemical contents. Further research is needed to determine chemical components of Salvadora persica which potential as tooth whitening.

\section{References}

1. Almas K. 1993. Miswak (chewing stick) and its role in oral health. Postgraduate Dentist, 3: 214-218.

2. Almas K. 1999. Miswak (chewing stick): A Cultural and Scientific Heritage. The Saudi Dental Journal, 11(2): 80-87.

3. Farooqi MIH, Srivastava JG. 1968. The toothbrush tree (Salvadoraperslca). Quart. J. Crude Drug Res, 8:1297-99

4. Al-Bagieh NH, Almas K. 1997. In vitro antimicrobial effects of aqueous and alcohol extracts of Miswak (chewing sticks). Cairo Dental Journal, 13(2):221-24.

5. Al-Lafi T, Ababneh H. 1995. The effect of the extract of the miswak (chewing sticks) used in Jordan and the Middle East on oral bacteria. International Dental Journal, 45(3):218-22.

6. Buadu CY, BokayeYodem AE. 1973. The antibacterial activity of some Ghanian chewing sticks. Ghana Pharmacological Journal, 1:150-53.

7. Rotimi VO, Mosadomi HA. 1987. The effect of crude extracts of nine African chewing sticks on oral anaerobes. Journal of Medical Microbiology, 23(1):55-60.

8. Gorlin RJ, Goldman HM. 1970. Environmental pathology of the teeth. In:Gorlin RJ, Goldman HM (ed) Thoma's Oral Pathology $6^{\text {th }}$ ed. Mosby Co. 
9. Addy M, Moran J. 1995. Mechanisms of stain formation on teeth, in particular associated with metal ions and antiseptics. Advanced Dental Restorative, 9: 450-456.

10. Watts A, Addy M. 2001. Tooth discolouration and staining: a review of the literature. Br Dent J, 190: 309-16.

11. Vogel RI. 1975. Intrinsic and extrinsic discoloration of the dentition. A review. Journal of Oral Medicine, 30: 99-104.

12. Walsh TF, Rawlinson A, Wildgoose D, Marlow I, Haywood J, Ward JM. 2005. Clinical evaluation of the stain removing ability of a whitening dentrifice and stain controlling system. Journal of Dentistry, 33(5): 413-418.

13. Pontefract $H$, Courtney $M$, Smith $S$, Newcombe RG, Addy M. 2004. Development of methods to enhance extrinsic tooth discoloration for comparison of toothpastes 2. Two-product clinical study. J ClinPeriodontol, 31: 7-11.

14. Lobene RA. 1968. Effect of dentifrices on tooth stain with controlled brushing. Journal of the American Dental Association, 77: 849-855.
15. Addy M, Prayitno S, Taylor L, Cadogan S. 1979. An in vitro study of the role of dietary factors in the etiology of tooth staining associated with the use of chlorhexidine. Journal of Periodontal Res, 14: 403-410.

16. Addy M, Moran J, Griffiths A, Wills-Wood NJ. 1985. Extrinsic tooth discolouration by metals and chlorhexidine. Br Dent J, 159: 331-334.

17. Addy M, Moran J. 1984. The formation of stain on acrylic surface by the interaction of cationic antiseptic mouthwash and tea. J of Biomed. Mat. Res, 18: 631-641.

18. Addy M, Goodfield S, Harrison A. 1991. The use of acrylic to compare the abrasivity and stain removal properties of toothpastes. Clinical $M a-$ terials, 7: 219-225.

19. Colgate World of Care; Colgate Oral Care Product; toothbrush, toothpaste and tooth whitening product. Retrieved 1 September 2008 from World Wide Web: http://www.colgate.com.my/ app/Colgate/MY/OC/Products/Toothpastes/ ColgateherbalWhite/FAQPage.cvsp

20. Richard RT, Robert WL, Brent M. 2003. An evaluation of technique to remove stains from teeth using microabrasion. Journal of American Dental Association, 134(8): 1066-107. 